\title{
Modeling to Predict Factor VIII Levels Associated with Zero Bleeds in Patients with Severe Hemophilia A Initiated on Tertiary Prophylaxis
}

\author{
Pratima Chowdary ${ }^{1}$ Kathelijn Fischer ${ }^{2}$ Peter W. Collins ${ }^{3}$ Amy Cotterill ${ }^{4}$ Barbara A. Konkle ${ }^{5,6}$ \\ Victor Blanchette ${ }^{7}$ Steven W. Pipe ${ }^{8}$ Erik Berntorp ${ }^{9}$ Martin Wolfsegger ${ }^{4}$ Werner Engl ${ }^{4}$ \\ Gerald Spotts ${ }^{10}$
}

${ }^{1}$ Katharine Dormandy Haemophilia and Thrombosis Centre, Royal Free London NHS Foundation Trust, London, United Kingdom

${ }^{2}$ Van Creveldkliniek, Department of Hematology, University Medical Center, Utrecht, The Netherlands

${ }^{3}$ School of Medicine, Cardiff University, Cardiff, United Kingdom

${ }^{4}$ Baxalta Innovations $\mathrm{GmbH}$, a member of the Takeda group of companies, Vienna, Austria

${ }^{5}$ Bloodworks Northwest, Seattle, Washington, United States

${ }^{6}$ Department of Medicine, University of Washington, Seattle, Washington, United States

7 Department of Paediatrics, Division of Haematology/Oncology, Hospital for Sick Children, University of Toronto, Toronto, Ontario, Canada

${ }^{8}$ Department of Pediatrics and Pathology, University of Michigan, Ann Arbor, Michigan, United States

${ }^{9}$ Department of Translational Medicine and Centre for Thrombosis and Haemostasis, Lund University, Malmö, Sweden

${ }^{10}$ Baxalta US Inc, a member of the Takeda group of companies, Lexington, Massachusetts, United States
Address for correspondence Pratima Chowdary, MBBS, MRCP, FRCPath, Katharine Dormandy Haemophilia and Thrombosis Centre, Royal Free Hospital, Pond Street, London NW3 2QG, United Kingdom (e-mail: p.chowdary@ucl.ac.uk).

\begin{abstract}
Keywords

- coagulation factors

- hemophilia A/B

- factor VIII

- pharmacodynamics
\end{abstract}

Background Factor VIII (FVIII) trough levels $>1 \mathrm{IU} / \mathrm{dL}$ in patients with severe hemophilia A receiving regular prophylaxis may optimize bleed protection.

Objectives In this post hoc analysis of patients receiving tertiary prophylaxis for approximately 1 year, the relationship between estimated FVIII levels and reported bleeds was investigated to predict the potential for zero bleeds.

Methods Sixty-three patients (median [range] age, 28 [7-59] years) with severe hemophilia A (229 bleeds) were included. FVIII levels at time of each bleed were estimated from single-dose individual pharmacokinetics. The highest estimated FVIII level at which patients experienced a bleed was considered the "potentially effective trough level" for that bleed type. Kaplan-Meier estimates of proportions of patients with no bleeds above certain estimated FVIII levels were determined. Those not experiencing a bleed in the trial were assumed to have a bleed at $0 \mathrm{IU} / \mathrm{dL}$ (pragmatic approach) or at their median trough level (conservative approach).

Results Kaplan-Meier estimates based on pragmatic approach predicted zero all bleeds, joint bleeds, and spontaneous joint bleeds in 1 year in 40, 43, and 63\% of patients, respectively, when the potentially effective trough FVIII level was set at received

November 22, 2019

accepted

February 20, 2020
DOI https://doi.org/

10.1055/s-0040-1709519.

ISSN 0340-6245. (c) 2020 Georg Thieme Verlag KG Stuttgart · New York
License terms

(1) (1) 
$1 \mathrm{IU} / \mathrm{dL}$. Between 1 and $10 \mathrm{IU} / \mathrm{dL}$, every $1 \mathrm{IU} / \mathrm{dL}$ rise in estimated FVIII level was associated with an additional $2 \%$ of patients having zero all bleeds.

Conclusion This post hoc analysis confirms benefits with trough levels of approximately 1 to $3 \mathrm{IU} / \mathrm{dL}$ in most patients starting tertiary prophylaxis; prophylaxis with higher trough levels may help patients to achieve zero bleeds.

\section{Introduction}

Patients with severe hemophilia A have a deficiency of coagulation factor VIII(FVIII) characterized by recurrent spontaneous and trauma-induced joint and soft-tissue bleeds. Hemarthroses cause progressive arthropathy, chronic pain, and musculoskeletal disability. ${ }^{1,2}$ Standard treatment is to reduce or prevent bleeds with regular infusions of FVIII, a practice called prophylaxis. Prophylactic infusions of FVIII should be started in young children before, or at the time of, their first hemarthrosis. ${ }^{3,4}$ In young children, this treatment strategy has been shown to reduce or prevent joint bleeds and arthropathy. ${ }^{5,6}$

The original concept for prophylaxis was to infuse FVIII on a regular basis to convert the bleeding phenotype from that of severe hemophilia to one of moderate hemophilia. The hypothesis was that maintaining the FVIII trough level $>1 \mathrm{IU} / \mathrm{dL}$ would limit the number of spontaneous joint bleeds and thus decrease joint damage. ${ }^{7}$ Although this practice is associated with a marked reduction in the number of bleeds, it does not completely eradicate spontaneous joint bleeds in all patients, and joint disease has still been observed in young adults over a 25- to 30year period. ${ }^{8,9}$ Although the role of the FVIII trough level in reducing the risk of breakthrough bleeding is undoubtedly important, other parameters that play a role are now known, including the amount of time spent at low FVIII levels ${ }^{10}$ and peak FVIII levels. ${ }^{11}$ The annualized number of joint bleeds experienced by a patient with hemophilia is related to their baseline FVIII level; the number of bleeds decreases rapidly as the FVIII level increases from $<1$ to approximately $3 \mathrm{IU} / \mathrm{dL}$, and continues to fall until the FVIII level has reached approximately $12 \mathrm{IU} / \mathrm{dL} .^{12}$

Prophylaxis is used routinely in children, and is now becoming standard care for adults with severe hemophilia A. ${ }^{13}$ If prophylaxis is started later in life, it is inevitable that arthropathy will have developed and target joints may be present. This may affect the efficacy of prophylaxis and influence the level of FVIII required to prevent bleeds.

The level of FVIII required to prevent all bleeds in patients with severe hemophilia $A$ is not well described and will vary between individuals (pharmacokinetic [PK] profile, level of activity). It is likely that patients starting tertiary prophylaxis will have active target joints with established arthropathy, and in this situation, higher FVIII levels may be needed to prevent spontaneous joint bleeds, at least initially. To investigate the relationship between FVIII levels and bleeds, we performed a post hoc analysis of data derived from a study of patients initiated on tertiary prophylaxis ${ }^{14}$ (i.e., regular continuous treatment started after the onset of joint disease documented by physical examination and plain radiographs of the affected joints ${ }^{15}$ ). The data set was used to predict FVIII trough levels that could be potentially effective in the prevention of all bleeds and spontaneous joint bleeds in patients receiving regular prophylaxis. Prevention of all bleeds is a measure of the overall protection provided and prevention of spontaneous bleeds is arguably the minimum outcome expected of a prophylactic treatment regimen.

\section{Methods}

\section{Clinical Study Summary}

Details of the prophylaxis study of antihemophilic factor (recombinant; ADVATE; Baxalta US Inc., a member of the Takeda group of companies, Lexington, Massachusetts, United States; NCT00243386) have been described previously. ${ }^{14}$ This multicenter, randomized, two-arm study compared annualized bleeding rates (ABRs) between two prophylactic treatment regimens (standard prophylaxis or PK-guided prophylaxis).

To meet key inclusion criteria for initiation of tertiary prophylaxis, patients needed to be aged $\geq 7$ and $<65$ years, have moderately severe or severe hemophilia A (baseline FVIII level $\leq 2 \mathrm{IU} / \mathrm{dL}$ ), have received on-demand treatment for $\geq 12$ months with a minimum of 150 exposure days to FVIII concentrates, and have had a minimum of eight joint hemorrhages before enrollment. Joint disease was inferred by the presence of target joints. After a washout period of $\geq 72$ hours, all enrolled patients underwent a PK study consisting of an intravenous bolus infusion with $50 \pm 5 \mathrm{IU} / \mathrm{kg}$ of antihemophilic factor (recombinant) followed by 10 postinfusion venous blood samples up to 48 hours after infusion. Of the 82 enrolled patients, 66 were randomized to one of the two prophylactic regimens following 6 months of on-demand treatment in the trial. The randomization at 6 months was stratified according to the presence of target joints, defined as joints in which at least four hemorrhages had occurred within a period of 6 months, or in which $>20$ lifetime hemarthroses had occurred. Patients assigned to standard prophylaxis received 20 to $40 \mathrm{IU} / \mathrm{kg}$ of antihemophilic factor (recombinant) every other day-the precise dosage determined by the investigator on the basis of the individual patient's FVIII half-life, incremental recovery, and clinical status. This resulted in a median measured FVIII trough level of $3 \mathrm{IU} / \mathrm{dL} .^{14}$ Patients assigned to PK-guided prophylaxis received 20 to $80 \mathrm{IU} / \mathrm{kg}$ of antihemophilic factor (recombinant) every 72 hours, with the aim of achieving a FVIII trough level of $1 \mathrm{IU} / \mathrm{dL}$.

\section{Post Hoc Analysis of the Relationship between Bleeds and Estimated FVIII Levels at the Time of Each Bleed}

This post hoc analysis only included patients with severe hemophilia A (defined as having at least one observed FVIII level of $<1 \mathrm{IU} / \mathrm{dL}$ during the study) who were treated with 
prophylaxis for $\geq 180$ days. Bleeds were self-reported by patients, and descriptions of bleeding episodes (including etiology [spontaneous and traumatic/injury-related], severity, and anatomical site[s]) were recorded in patient diaries and verified by the investigator. The severity of the bleeding episode was determined by the following scale: (1) minor: little or no pain; little or no change in the range of motion of affected joint (if joint bleeding event); mild restriction of mobility and activity; (2) moderate: mild to moderate pain; some decrease in range of motion of affected joint (if joint bleeding event); moderate decrease in mobility and activity; and (3) major/lifethreatening: significant pain; substantial decrease in range of motion of affected joint (if joint bleeding event); incapacity; life threatening.

A total of 63 patients and 229 bleeds were eligible for analysis. Of the 63 patients included in the analysis, 41 recorded at least one bleed during the prophylactic treatment period.

\section{Estimation of FVIII Level at the Time of Each Bleed}

Patient-specific PK profiles were obtained from the patients' FVIII activity level measurements collected during the PK study. Each patient had between 7 and 10 postinfusion FVIII activity level measurements. A two-compartmental model, parameterized in terms of macro constants with a Poisson error, was fitted independently to the postinfusion PK data from each patient using iteratively reweighted least squares with SAS (Base SAS 9.3 Procedures Guide, Second Edition, and SAS/STAT 12.1 User's Guide; 2012; SAS Institute Inc., Cary, North Carolina, United States) and R ( $R$ : a language and environment for statistical computing; 2019; R Development Core Team, R Foundation for Statistical Computing, Vienna, Austria). If this model did not converge, or the resulting estimates (such as those of FVIII half-life) were unrealistic, then a one-compartmental model, also parameterized in terms of macro constants with a Poisson error, was fitted using iteratively reweighted least squares. The goodness-of-fit plots were examined to deem the suitability of this model. There were 12 missing date-time values for bleeds and 9 missing date-time values for infusions; these values were imputed using an algorithm based on median values for the analysis. A sensitivity analysis was undertaken to understand the impact of imputed date-time values, which was found to be minimal when the analysis was rerun, with entries with missing date-time values deleted.

The individually fitted PK model, along with the dose and time of prophylactic infusions, was used to model the FVIII activity levels through the duration of the study for each patient. This model was used to estimate the FVIII level at the time of each bleed as reported by the patient.

Estimation of the FVIII level at the time of each bleed was based on the following assumptions:

1. The FVIII activity level-time profile could be suitably characterized by a compartmental model.

2. PK were linear, implying dose-proportionality.

3. There was no interoccasion variability: this is negligible on the basis of Björkman et al. ${ }^{16}$

4. Residual FVIII activity level was suitably accounted for under the principle of superposition.
5. The constant underlying risk of bleed for each patient (i.e., physical activity or sports) was not taken into account.

\section{Modeling Bleed Prevention in Relation to Estimated FVIII Levels Associated with Bleeds}

Three bleed types were considered in the analyses: all bleeds, joint bleeds, and spontaneous joint bleeds. For each patient, the highest FVIII activity level at which they experienced each type of bleed during prophylactic treatment was considered their "potentially effective trough level" for that bleed type, above which the patient would likely be bleed free.

During prophylactic treatment, some patients did not experience any bleeds at all, whereas others did not experience bleeds of certain types. To avoid biasing the results by removing patients from the analysis who did not experience a bleed (type), an assumption was made regarding the level at which these patients may be expected to bleed (if FVIII trough levels dropped below a certain threshold). Analyses were performed using pragmatic and conservative approaches for these patients:

\section{Pragmatic ("Best-Case") Approach}

The pragmatic approach assumed that patients who did not experience a bleed (type) would have had a bleed (of that type) only if their FVIII level was $0 \mathrm{IU} / \mathrm{dL}$. Doses were selected to achieve a trough level of $1 \mathrm{IU} / \mathrm{dL}$ (known to be associated with decreased bleeding tendency); therefore, not all patients would be expected to experience levels of $<1 \mathrm{IU} / \mathrm{dL}$ during the period of prophylaxis. ${ }^{10,12,17}$

\section{Conservative ("Worst-Case") Approach}

The conservative approach assumed that patients who did not experience a bleed (type) would have had a bleed (of that type) if their FVIII level fell below their median estimated trough level. This approach errs on the side of caution because patients did not actually experience a bleed at their median trough level; it assumes that FVIII levels maintained throughout the period of prophylaxis were at least equal to or greater than the median trough level.

\section{Results}

\section{Patient Characteristics}

Of the 66 patients with severe $(n=58)$ or moderately severe $(n=8)$ hemophilia A randomized to one of the prophylactic regimens, 63 were considered in this analysis because they received $>180$ days of prophylaxis. Of these 63 patients, 59 received prophylaxis for 365 days $\pm 10 \%$. The characteristics of the cohort included are detailed in -Table 1.

During the prophylaxis period of the study, 22 patients (34.9\%) did not report any bleeds, whereas the remaining 41 patients experienced at least one bleed. A total of 26 patients (41.3\%) experienced at least one spontaneous joint bleed, whereas 37 patients (58.7\%) did not record any spontaneous joint bleeds during the study period on prophylaxis. At study entry, only 3 patients had no target joints and 60 patients had between 1 and 10 target joints (median, 3). 
Table 1 Patient characteristics

\begin{tabular}{|c|c|c|}
\hline Parameter & Mean \pm SD & Median (range) \\
\hline Age (y) & $30.32 \pm 12.61$ & $28(7-59)$ \\
\hline Weight (kg) & $70.98 \pm 15.47$ & $71(18.7-120)$ \\
\hline $\begin{array}{l}\text { Number of } \\
\text { target joints }^{\text {a }}\end{array}$ & $3.49 \pm 2.12$ & $3(0-10)$ \\
\hline FVIII $t_{1 / 2}$ for the group & $12.18 \pm 3.21$ & $\begin{array}{l}12.25 \\
(7.28-21.89)\end{array}$ \\
\hline \multicolumn{3}{|l|}{ On-demand period } \\
\hline ABR of all bleeds & $50.04 \pm 21.56$ & $\begin{array}{l}45.89 \\
(13.04-121.13)\end{array}$ \\
\hline ABR of joint bleeds & $43.53 \pm 21.00$ & $\begin{array}{l}39.13 \\
(6.52-115.54)\end{array}$ \\
\hline $\begin{array}{l}\text { ABR of spontaneous } \\
\text { joint bleeds }\end{array}$ & $31.90 \pm 18.52$ & $\begin{array}{l}29.94 \\
(0-91.31)\end{array}$ \\
\hline \multicolumn{3}{|l|}{ Prophylaxis period } \\
\hline ABR of all bleeds & $2.10 \pm 4.22$ & $0(0-17.11)$ \\
\hline ABR of joint bleeds & $1.94 \pm 3.99$ & $0(0-17.11)$ \\
\hline $\begin{array}{l}\text { ABR of spontaneous } \\
\text { joint bleeds }\end{array}$ & $0.97 \pm 2.21$ & $0(0-10.23)$ \\
\hline
\end{tabular}

Abbreviations: ABR, annualized bleeding rate; FVIII, factor VIII; SD, standard deviation; $t_{1 / 2}$, half-life.

${ }^{\mathrm{a}}$ Target joints were defined as joints in which $\geq 4$ hemorrhages had occurred within a period of 6 months, or in which $>20$ lifetime hemarthroses had occurred.

\section{Bleed Details}

A total of 229 bleeds were considered in this analysis, of which 200 were joint bleeds and 105 were spontaneous joint bleeds. The location, severity, and etiology of the bleeds are described in - Table 2 .

Estimated FVIII Levels in Relation to Reported Bleeds The estimated FVIII levels at which bleeds occurred against the time at which bleeds occurred after infusion of antihemophilic factor (recombinant) are shown in -Fig. 1, for all bleeds observed during prophylaxis. Bleeds were reported at FVIII levels up to $60 \mathrm{IU} / \mathrm{dL}$, with spontaneous joint bleeds only occurring below a FVIII level of $35 \mathrm{IU} / \mathrm{dL}$.

\section{Relationship between Estimated FVIII Levels and Bleeds}

The proportion of patients who would experience zero bleeds in a year if their trough FVIII levels were maintained above the potentially effective trough level was estimated for each bleed type, using the pragmatic and conservative approaches described earlier. This information is presented by bleed type in -Tables 3 and 4. It is also presented graphically using Kaplan-Meier curves for all bleeds and spontaneous joint bleeds in -Figs. $\mathbf{2}$ and 3, respectively. For each bleed type, results are presented under the pragmatic and conservative approach on the same plot, for comparison.

The analysis that utilized the pragmatic approach indicated that 40,43 , and $63 \%$ of the patients were expected to have zero all bleeds, joint bleeds, or spontaneous joint bleeds while
Table 2 Bleed details by location and severity

\begin{tabular}{|l|l|l|l|}
\hline \multirow{2}{*}{} & \multicolumn{3}{l}{ Bleed location, $\boldsymbol{n}(\%)$} \\
\cline { 2 - 4 } & Total & Joint & Nonjoint \\
\hline Type & 229 & 200 & 29 \\
\hline Total & 116 & 105 & 11 \\
\hline Spontaneous & 113 & 95 & 18 \\
\hline Traumatic & \multicolumn{4}{l|}{} \\
\hline Severity assessment for total bleeds $(n=229)$ \\
\hline Mild & $78(34.1)$ & $59(29.5)$ & $19(65.5)$ \\
\hline Moderate & $127(55.5)$ & $121(60.5)$ & $6(21.0)$ \\
\hline Severe & $15(6.6)$ & $14(7.0)$ & $1(3.5)$ \\
\hline Missing & $9(3.9)$ & $6(3.0)$ & $3(10.0)$ \\
\hline Severity assessment for spontaneous bleeds $(n=116)$ \\
\hline Mild & $36(31.0)$ & NA & NA \\
\hline Moderate & $71(61.2)$ & NA & NA \\
\hline Severe & $7(6.0)$ & NA & NA \\
\hline Missing & $2(1.7)$ & NA & NA \\
\hline Severity assessment for traumatic bleeds $(n=113)$ \\
\hline Mild & $42(37.2)$ & NA & NA \\
\hline Moderate & $56(49.6)$ & NA & NA \\
\hline Severe & $8(7.1)$ & NA & NA \\
\hline Missing & $7(6.2)$ & NA & NA \\
\hline
\end{tabular}

Abbreviation: NA, not available.

maintaining a trough level of $1 \mathrm{IU} / \mathrm{dL}$. With the conservative approach, similar outcomes were derived at around $3 \mathrm{IU} / \mathrm{dL}$ for all bleeds and joint bleeds, and at $5 \mathrm{IU} / \mathrm{dL}$ for spontaneous joint bleeds. A measurable level of $1 \mathrm{IU} / \mathrm{dL}$ provided substantial benefit in the prevention of bleeds, and higher levels were associated with smaller incremental benefits.

When a modeled FVIII level was set as a trough level between 1 and $10 \mathrm{IU} / \mathrm{dL}$, under the pragmatic approach, a $1 \mathrm{IU} / \mathrm{dL}$ increase in FVIII level was associated with a $2 \%$ increase in the number of patients who might achieve zero bleeds in a year. No bleeds occurred between estimated FVIII trough levels of 10 and $12 \mathrm{IU} / \mathrm{dL}$.

Further, there was no obvious difference in the estimates between the two approaches when the modeled FVIII level exceeded $10 \mathrm{IU} / \mathrm{dL}$, the level at which near maximal efficacy was seen. Continuing with the pragmatic approach, beyond a modeled FVIII level of $10 \mathrm{IU} / \mathrm{dL}$, for every $10 \mathrm{IU} / \mathrm{dL}$ increase, we might expect on average a 10 to $15 \%$ change in the proportion of patients achieving zero bleeds in a year, depending on the bleed type; after 30\% there was minimal gain. The proportion predictions at the higher FVIII levels had wide confidence intervals, and indeed, the potential for misreporting pain as bleeds increased with increasing FVIII levels.

\section{Discussion}

In this post hoc analysis of patients with severe hemophilia $A$ with multiple target joints initiated on tertiary prophylaxis, 


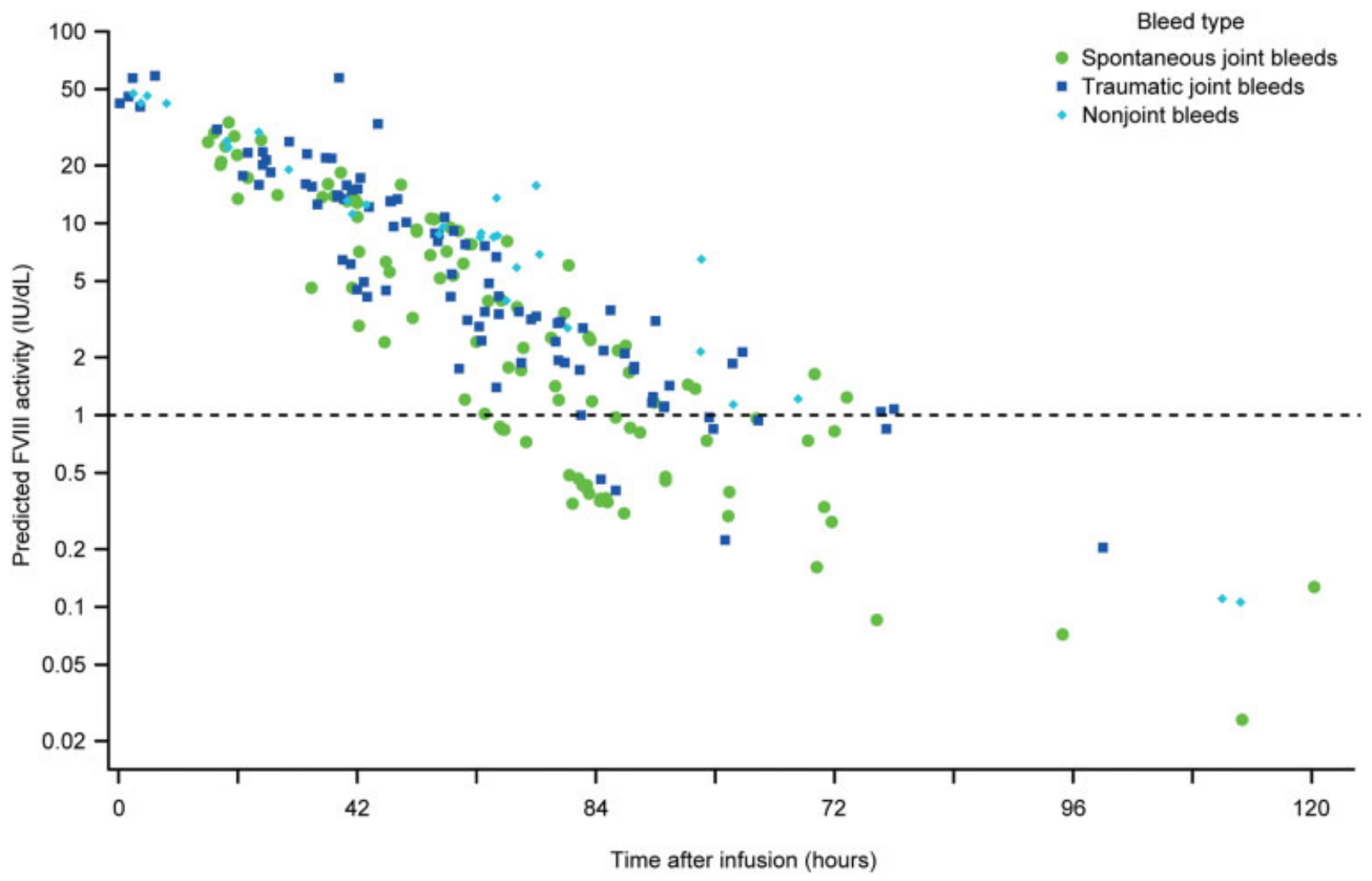

Fig. 1 Predicted factor VIII (FVIII) activity levels at the time of each bleed.

Table 3 Pragmatic approach for the prediction of zero all bleeds, joint bleeds, and spontaneous joint bleeds in a year, according to estimated FVIII levels

\begin{tabular}{|c|c|c|c|c|c|c|c|c|c|}
\hline \multirow{4}{*}{$\begin{array}{l}\text { Estimated FVIII activity } \\
\text { level (IU/dL) } \\
1\end{array}$} & \multicolumn{9}{|c|}{ Patients with zero bleeds (\%) } \\
\hline & \multicolumn{3}{|l|}{ All bleeds } & \multicolumn{3}{|l|}{ Joint bleeds } & \multicolumn{3}{|c|}{ Spontaneous joint bleeds } \\
\hline & \multirow{2}{*}{$\begin{array}{l}\text { Proportion } \\
39.7\end{array}$} & \multicolumn{2}{|c|}{$\begin{array}{l}95 \% \mathrm{Cl} \text { for } \\
\text { proportion }\end{array}$} & \multirow{2}{*}{$\begin{array}{l}\text { Proportion } \\
42.9\end{array}$} & \multicolumn{2}{|c|}{$\begin{array}{l}95 \% \mathrm{Cl} \text { for } \\
\text { proportion }\end{array}$} & \multirow{2}{*}{$\begin{array}{l}\text { Proportion } \\
63.5\end{array}$} & \multicolumn{2}{|c|}{$\begin{array}{l}95 \% \mathrm{Cl} \text { for } \\
\text { proportion }\end{array}$} \\
\hline & & 28.5 & 52.0 & & 31.4 & 55.1 & & 51.2 & 74.3 \\
\hline 3 & 44.4 & 32.9 & 56.7 & 47.6 & 35.8 & 59.7 & 68.3 & 56.0 & 78.4 \\
\hline 5 & 50.8 & 38.8 & 62.7 & 54.0 & 41.8 & 65.7 & 71.4 & 59.3 & 81.1 \\
\hline 10 & 60.3 & 48.0 & 71.5 & 63.5 & 51.2 & 74.3 & 79.4 & 67.8 & 87.5 \\
\hline 12 & 60.3 & 48.0 & 71.5 & 63.5 & 51.2 & 74.3 & 79.4 & 67.8 & 87.5 \\
\hline 15 & 66.7 & 54.4 & 77.1 & 69.8 & 57.6 & 79.8 & 85.7 & 75.0 & 92.3 \\
\hline 20 & 74.6 & 62.7 & 83.7 & 76.2 & 64.4 & 85.0 & 88.9 & 78.8 & 94.5 \\
\hline 30 & 88.9 & 78.8 & 94.5 & 88.9 & 78.8 & 94.5 & 98.4 & 91.5 & 99.7 \\
\hline 40 & 90.5 & 80.7 & 95.6 & 90.5 & 80.7 & 95.6 & 100.0 & 94.3 & 100.0 \\
\hline 50 & 95.2 & 86.9 & 98.4 & 95.2 & 86.9 & 98.4 & 100.0 & 94.3 & 100.0 \\
\hline 60 & 100.0 & 94.3 & 100.0 & 100.0 & 94.3 & 100.0 & 100.0 & 94.3 & 100.0 \\
\hline
\end{tabular}

Abbreviations: $\mathrm{Cl}$, confidence interval; FVIII, factor VIII.

Note: The estimated FVIII level is the assumed effective FVIII level specific to the individual and type of bleed.

the proportions of the cohort that would have been bleed free if the estimated FVIII level of $1 \mathrm{IU} / \mathrm{dL}$ was set as the lowest FVIII level of clinical interest (i.e., trough level) were $40 \%$ for all bleeds, $43 \%$ for joint bleeds, and $63 \%$ for spontaneous joint bleeds.
For all bleeds, a $1 \%$ rise in the modeled FVIII level between 1 and $10 \mathrm{IU} / \mathrm{dL}$ increased the proportion of the cohort achieving zero all bleeds by approximately $2 \%$. At a modeled FVIII level of $10 \mathrm{IU} / \mathrm{dL}$ using the pragmatic approach, $60.3 \%$ of patients recently initiated on tertiary prophylaxis were 
Table 4 Conservative approach for the prediction of zero all bleeds, joint bleeds, and spontaneous joint bleeds in a year, according to estimated FVIII levels

\begin{tabular}{|c|c|c|c|c|c|c|c|c|c|}
\hline \multirow{4}{*}{$\begin{array}{l}\text { Estimated FVIII } \\
\text { activity level (IU/dL) } \\
1\end{array}$} & \multicolumn{9}{|c|}{ Patients with zero bleeds (\%) } \\
\hline & \multicolumn{3}{|l|}{ All bleeds } & \multicolumn{3}{|l|}{ Joint bleeds } & \multicolumn{3}{|c|}{ Spontaneous joint bleeds } \\
\hline & \multirow{2}{*}{$\begin{array}{l}\text { Proportion } \\
19.1 \\
\end{array}$} & \multicolumn{2}{|c|}{$\begin{array}{l}95 \% \mathrm{Cl} \text { for } \\
\text { proportion }\end{array}$} & \multirow{2}{*}{$\begin{array}{l}\text { Proportion } \\
19.1\end{array}$} & \multicolumn{2}{|c|}{$\begin{array}{l}95 \% \mathrm{Cl} \text { for } \\
\text { proportion }\end{array}$} & \multirow{2}{*}{$\begin{array}{l}\text { Proportion } \\
27.0\end{array}$} & \multicolumn{2}{|c|}{$\begin{array}{l}95 \% \mathrm{Cl} \text { for } \\
\text { proportion }\end{array}$} \\
\hline & & 11.3 & 30.4 & & 11.3 & 30.4 & & 17.6 & 39.0 \\
\hline 3 & 36.5 & 25.7 & 48.9 & 36.5 & 25.7 & 48.9 & 50.8 & 38.8 & 62.7 \\
\hline 5 & 47.6 & 35.8 & 59.7 & 49.2 & 37.3 & 61.2 & 63.5 & 51.2 & 74.3 \\
\hline 10 & 60.3 & 48.0 & 71.5 & 61.9 & 49.6 & 72.9 & 77.8 & 66.1 & 86.3 \\
\hline 12 & 60.3 & 48.0 & 71.5 & 61.9 & 49.6 & 72.9 & 77.8 & 66.1 & 86.3 \\
\hline 15 & 66.7 & 54.4 & 77.1 & 69.8 & 57.6 & 79.8 & 85.7 & 75.0 & 92.3 \\
\hline 20 & 74.6 & 62.7 & 83.7 & 76.2 & 64.4 & 85.0 & 88.9 & 78.8 & 94.5 \\
\hline 30 & 88.9 & 78.8 & 94.5 & 88.9 & 78.8 & 94.5 & 98.4 & 91.5 & 99.7 \\
\hline 40 & 90.5 & 80.7 & 95.6 & 90.5 & 80.7 & 95.6 & 100.0 & 94.3 & 100.0 \\
\hline 50 & 95.2 & 86.9 & 98.4 & 95.2 & 86.9 & 98.4 & 100.0 & 94.3 & 100.0 \\
\hline 60 & 100.0 & 94.3 & 100.0 & 100.0 & 94.3 & 100.0 & 100.0 & 94.3 & 100.0 \\
\hline
\end{tabular}

Abbreviations: $\mathrm{Cl}$, confidence interval; FVIII, factor VIII.

Note: The estimated FVIII level is the assumed effective FVIII level specific to the individual and type of bleed.

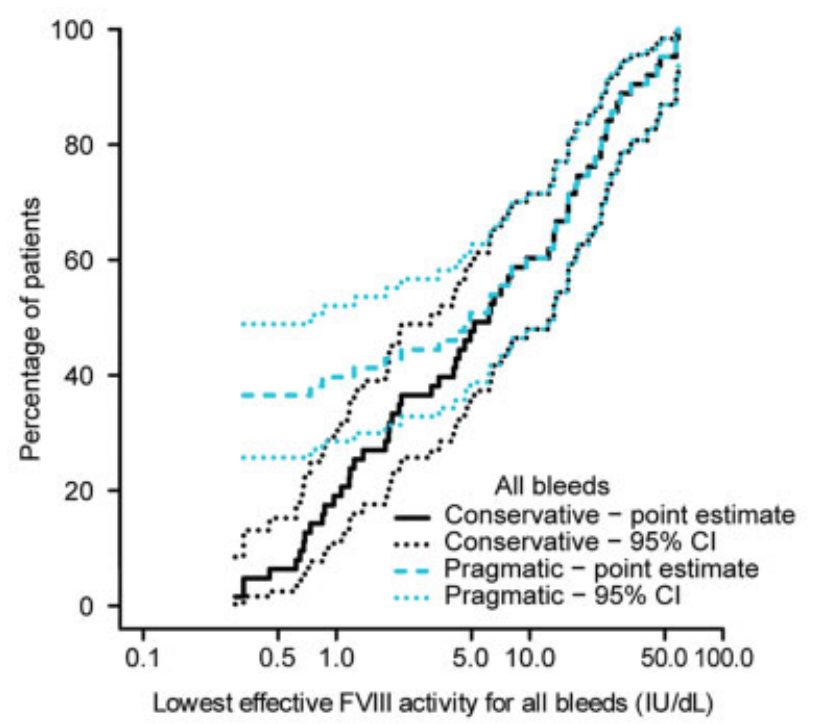

Fig. 2 Comparison of the pragmatic and conservative approaches, showing the proportion of the cohort predicted to have zero all bleeds according to factor VIII (FVIII) levels of clinical interest (the minimum effective estimated FVIII level specific to the individual and the type of bleed).

expected to have zero all bleeds, $63.5 \%$ were estimated to have zero joint bleeds, and $79.4 \%$ were estimated to have zero spontaneous joint bleeds. Above a modeled FVIII level of $10 \mathrm{IU} / \mathrm{dL}$, the reductions in bleeds were less substantial. However, bleeds were also reported at much higher modeled FVIII levels in some patients, even outside the range of FVIII levels associated with hemophilia (0-40 IU/dL).

These data are similar to those published in another post hoc analysis of 143 previously treated patients in three pivotal clinical studies of antihemophilic factor (recombinant) ${ }^{10}$ In

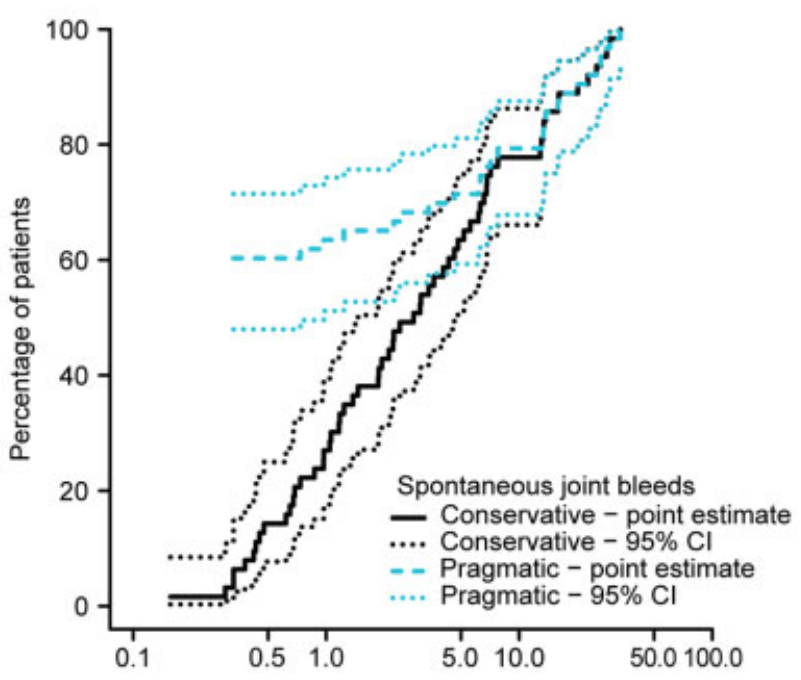

Lowest effective FVIII activity for spontaneous joint bleeds (IU/dL)

Fig. 3 Comparison of the pragmatic and conservative approaches, showing the proportion of the cohort predicted to have zero spontaneous joint bleeds according to factor VIII (FVIII) levels of clinical interest (the minimum effective estimated FVIII level specific to the individual and the type of bleed).

the pivotal antihemophilic factor (recombinant) cohort, the median ABR in children was 3.1 (patients aged 1-6 years, $n=44$, arthropathy $2 \%$, adherence $89 \%$, zero ABR $25 \%$ ) and in adolescents and adults it was similar at a median of 3.3 (patients aged 10-65 years, $n=99$, arthropathy 67\%, adherence $78 \%$, zero ABR $16 \%$ ). A multivariate analysis predicted the probability of having zero bleeds when patients spent no time with FVIII levels $<1 \mathrm{IU} / \mathrm{dL}$ during prophylaxis to be $55 \%$ for adults (vs. $40 \%$ in this analysis, where the regimen was optimized to achieve a trough level of $1 \%$ ) and $90 \%$ for children. 
The increasing bleed rate in adolescents and adults in addition to its association with increasing time spent at a FVIII level $<1 \mathrm{IU} / \mathrm{dL}$ was also inversely related to the average frequency of infusions, which is logical if one considers that frequency and adherence to frequency have the greatest impact on trough levels. The higher ABRs in adolescents and adults may potentially be related to their physical activity and arthropathy, implying a potential role for other nonhematological factors in bleed prevention, particularly in adolescents and adults. ${ }^{18}$

One nonhematological factor that has been studied in children with hemophilia receiving regular prophylaxis is the transient increase in the risk of bleeding associated with vigorous physical activity. ${ }^{19}$ The authors noted that most bleeds associated with physical activity were manifest within 1 hour of activity and the National Hemophilia Foundation risk categorization was used to categorize physical activity. ${ }^{20}$ Category 2 and 3 physical activities were associated with a transient increase in the risk of bleeding, with odds ratios of 2.7 and 3.7, respectively. The data demonstrate a moderate increase in relative risk, however, the absolute increase was low. Further, the bleeding incidence was lower by $2 \%$ for every $1 \mathrm{IU} / \mathrm{dL}$ increase in clotting factor level. These results are similar to those demonstrated in this cohort with the pragmatic approach, where every $1 \mathrm{IU} / \mathrm{dL}$ increase in the modeled FVIII level $>1 \mathrm{IU} / \mathrm{dL}$ was associated with a lower bleed rate and a $2 \%$ increase in the proportion of the cohort predicted to have zero joint bleeds, both spontaneous and traumatic; however, the nature of activity responsible for the traumatic bleeds was not categorized in the study.

A major limitation of this analysis is the assumption that bleed risk is independent of time and activity. Other confounding factors in the analysis include the different trough levels and bleeding risk per patient, the varying observation period per patient, and the need for imputation to provide bleed-rate estimates in relation to set FVIII levels. Other limitations include the presence of active target joints at enrollment, because the Kaplan-Meier estimates in this analysis are for the first year of tertiary prophylaxis and estimates for subsequent years may change, as it is well known that the cohort's median ABR decreased with increasing length of time spent on prophylaxis. ${ }^{21}$ In addition, all bleeds were self-reported and, in patients with chronic arthropathy, it is not uncommon for arthritic pain to be misinterpreted as early bleeds: previous studies have shown that this may be the case in as many as one-third of all bleeds. ${ }^{22,23}$ Further, patients have been educated to treat when in doubt and it is likely that the reported bleeds at high FVIII levels were probably not true bleeds. Similarly, there may be underreporting of bleeding events toward the tail end of the prophylaxis period when the next infusion was due. This limitation applies to almost all studies in the field.

The analysis confirms that the greatest benefit is seen at FVIII levels of approximately $1 \mathrm{IU} / \mathrm{dL}$, which is the first target in the prophylactic management of hemophilia A. ${ }^{1,10}$ The analysis also confirms the results from the post hoc analysis of the antihemophilic factor (recombinant) pivotal cohort ${ }^{10}$ and is congruent with the findings published on the natural history of joint bleeding in patients with mild, moderate, and severe hemophilia receiving prophylaxis. ${ }^{12}$ It also supports the role of other factors in the development of bleeds, potentially including activity and trauma. ${ }^{9,18}$ This multifactorial pathogenesis of bleeds underlies the philosophy of personalized prophylaxis that considers other determinants in designing the optimal prophylaxis regimen, including personalized trough levels for patients. $9,24,25$

Higher peak and trough levels can be achieved either empirically and through the calculation of half-life with formal PK analysis, or through Bayesian analysis. ${ }^{16,26-30}$ The benefit of higher trough levels has been observed in post hoc analyses of various cohort studies. In addition, this hypothesis was tested in a randomized controlled trial comparing trough levels of 1 to $3 \mathrm{IU} / \mathrm{dL}$ versus 8 to $12 \mathrm{IU} / \mathrm{dL}$ (NCT02585960). ${ }^{31}$

In conclusion, this post hoc analysis confirms previous observations with regard to the FVIII level of $1 \mathrm{IU} / \mathrm{dL}$ where maximum benefit is seen. However, to prevent all spontaneous joint bleeds, some patients may require higher FVIII levels, which can be determined on the basis of clinical outcomes and PK evaluation.

\section{What is known about this topic?}

- Prophylaxis in severe hemophilia A increasingly targets factor VIII (FVIII) troughs $\geq 1 \mathrm{IU} / \mathrm{dL}$.

- Data on tertiary prophylaxis can be used to model FVIII trough levels and zero bleeding.

\section{What does this paper add?}

- Modeling showed greatest benefit with FVIII trough levels of $1-3 \mathrm{IU} / \mathrm{dL}$.

- FVIII $>3 \mathrm{IU} / \mathrm{dL}$ was associated with an extra $2 \%$ of patients with no bleeds per $1 \mathrm{IU} / \mathrm{dL}$ rise.

\section{Authors' Contributions}

P.C., K.F., P.W.C., and G.S. jointly designed the analysis, interpreted the results, and wrote the first draft of the manuscript. A.C. performed the statistical analysis and discussed and interpreted the results. B.A.K., V.B., and S.W.P. discussed and interpreted the results. E.B. participated in designing the study and discussed and interpreted the results. M.W. performed the PK analysis and discussed and interpreted the results. W.E. revised the graphical representation of results and discussed and interpreted the results. All authors reviewed the manuscript drafts and approved the final version.

\section{Funding}

This study was funded by Baxalta US Inc, a member of the Takeda group of companies, Lexington, Massachusetts, United States. 


\section{Conflict of Interest}

All authors report nonfinancial (medical writing) support from Baxalta US Inc., a Takeda company, during the conduct of the study. P.C. has received consulting fees from Bayer, Baxalta*, Biogen, Biovertiv, CSL Behring, Chugai, Freeline, Novo Nordisk, Pfizer, Roche, Shire", Spark and Sobi; and research funding from CSL Behring, Novo Nordisk, and Pfizer. K.F. has received consulting fees from Bayer, Baxter ${ }^{*}$, Biogen, Freeline, Novo Nordisk, and Pfizer; research funding from Bayer, Baxter, Novo Nordisk, and Wyeth/Pfizer; and has been a member of speaker bureaus for Bayer, Baxter*, Biotest Octapharma, CSL Behring, Novo Nordisk, and Pfizer. P.W.C. has received consulting fees from CSL Behring, Novo Nordisk, Shire*, and Sobi; research funding from CSL Behring; and has been a member of a speaker bureau for Shire*. At the time of the current study, A.C. was an employee of Baxalta Innovations $\mathrm{GmbH}$, a member of the Takeda group of companies. B.A.K. has received consulting fees from BioMarin, Genentech, Sigilon, and Spark; and research funding from Bioverativ, Pfizer, Sangamo, Shire , and Spark. V.B. has served as Chair of the International Prophylaxis Study Group (supported by grants to the Hospital for Sick Children Foundation, Toronto, Canada, from Bayer HealthCare, Bioverativ, Novo Nordisk, Pfizer, Shire*, and Spark); has served on data safety monitoring boards for Octapharma and Shire; has served on speaker bureaus/advisory boards for Amgen, Bayer HealthCare, Novo Nordisk, Pfizer, and Shire*; and has received research support from Bayer HealthCare, Bioverativ, and Shire*. S.W.P. has received consulting fees from Apcintex, Bayer, BioMarin, Bioverativ, Catalyst Biosciences, CSL Behring, HEMA Biologics, Freeline, Novo Nordisk, Pfizer, Roche/Genentech, Sanofi, Shire*, Spark, and uniQure. E.B. has received research funding from Bayer, CSL Behring, Shire*, and Sobi; has been a member of speaker bureaus from Bayer, Octapharma, and Shire*; and has served on an advisory board for LFB. M.W. and W. E. are employees of Baxalta Innovations $\mathrm{GmbH}$, a member of the Takeda group of companies, and are Takeda stock owners. At the time of the current study, G.S. was an employee of Baxalta US Inc, a member of the Takeda group of companies.

"A member of the Takeda group of companies.

\section{Acknowledgment}

Editorial assistance in formatting and copy-editing of this manuscript was provided by Andy Brown, PhD, CMPP, and Margit Rezabek, DVM, PhD, CMPP, employees of Excel Medical Affairs (Fairfield, Connecticut, United States) and was funded by Baxalta US Inc, a member of the Takeda group of companies, Lexington, Massachusetts, United States.

\section{References}

1 Ahlberg A. Haemophilia in Sweden. VII. Incidence, treatment and prophylaxis of arthropathy and other musculo-skeletal manifestations of haemophilia A and B. Acta Orthop Scand Suppl 1965; (Suppl 77):3-132
2 Aledort LM, Haschmeyer RH, Pettersson H; The Orthopaedic Outcome Study Group. A longitudinal study of orthopaedic outcomes for severe factor-VIII-deficient haemophiliacs. J Intern Med 1994;236(4):391-399

3 Fischer K, Collins PW, Ozelo MC, Srivastava A, Young G, Blanchette VS. When and how to start prophylaxis in boys with severe hemophilia without inhibitors: communication from the SSC of the ISTH. J Thromb Haemost 2016;14(5):1105-1109

4 Richards M, Williams M, Chalmers E, et al; Paediatric Working Party of the United Kingdom Haemophilia Doctors' Organisation. A United Kingdom Haemophilia Centre Doctors' Organization guideline approved by the British Committee for Standards in Haematology: guideline on the use of prophylactic factor VIII concentrate in children and adults with severe haemophilia $\mathrm{A}$. Br J Haematol 2010;149(4):498-507

5 Manco-Johnson MJ, Abshire TC, Shapiro AD, et al. Prophylaxis versus episodic treatment to prevent joint disease in boys with severe hemophilia. N Engl J Med 2007;357(6):535-544

6 Gringeri A, Lundin B, von Mackensen S, Mantovani L, Mannucci PM; ESPRIT Study Group. A randomized clinical trial of prophylaxis in children with hemophilia A (the ESPRIT Study). J Thromb Haemost 2011;9(4):700-710

7 Nilsson IM, Berntorp E, Löfqvist T, Pettersson H. Twenty-five years' experience of prophylactic treatment in severe haemophilia A and B. J Intern Med 1992;232(1):25-32

8 Mazepa MA, Monahan PE, Baker JR, Riske BK, Soucie JM; US Hemophilia Treatment Center Network. Men with severe hemophilia in the United States: birth cohort analysis of a large national database. Blood 2016;127(24):3073-3081

9 Oldenburg J. Optimal treatment strategies for hemophilia: achievements and limitations of current prophylactic regimens. Blood 2015;125(13):2038-2044

10 Collins PW, Blanchette VS, Fischer K, et al; rAHF-PFM Study Group. Break-through bleeding in relation to predicted factor VIII levels in patients receiving prophylactic treatment for severe hemophilia A. J Thromb Haemost 2009;7(3):413-420

11 Valentino LA, Pipe SW, Collins PW, et al. Association of peak factor VIII levels and area under the curve with bleeding in patients with haemophilia A on every third day pharmacokinetic-guided prophylaxis. Haemophilia 2016;22(4):514-520

12 Den Uijl IE, Mauser Bunschoten EP, Roosendaal G, et al. Clinical severity of haemophilia A: does the classification of the 1950s still stand? Haemophilia 2011;17(6):849-853

13 Gringeri A, Lambert T, Street A, Aledort L; Adolescent/Adult Prophylaxis Expert Working Group of the International Prophylaxis Study Group. Tertiary prophylaxis in adults: is there a rationale? Haemophilia 2012;18(5):722-728

14 Valentino LA, Mamonov V, Hellmann A, et al; Prophylaxis Study Group. A randomized comparison of two prophylaxis regimens and a paired comparison of on-demand and prophylaxis treatments in hemophilia A management. J Thromb Haemost 2012;10 (3):359-367

15 Srivastava A, Brewer AK, Mauser-Bunschoten EP, et al; Treatment Guidelines Working Group on Behalf of The World Federation of Hemophilia. Guidelines for the management of hemophilia. Haemophilia 2013;19(1):e1-e47

16 Björkman S, Oh M, Spotts G, et al. Population pharmacokinetics of recombinant factor VIII: the relationships of pharmacokinetics to age and body weight. Blood 2012;119(2):612-618

17 Ahlberg A, Nilsson IM, Bauer GC. Use of antihemophilic factor (plasma fraction I-O) during correction of knee-joint deformities in hemophilia A. Report of three cases including one osteotomy. J Bone Joint Surg Am 1965;47:323-332

18 McCarthy A, Moore A, Redhead L, McLaughlin P, Iorio A, Chowdary P. Development of haemophilic arthropathy of the ankle: results of a Delphi consensus survey on potential contributory factors. Haemophilia 2015;21(1):116-123 


\section{Modeling to Predict Effective Factor VIII Levels Chowdary et al.}

19 Broderick CR, Herbert RD, Latimer J, et al. Association between physical activity and risk of bleeding in children with hemophilia. JAMA 2012;308(14):1452-1459

20 Anderson A, Forsyth A. Playing it safe: bleeding disorders, sports and exercise: National Haemophilia Foundation; 2017 Available at: https://www.hemophilia.org/sites/default/files/document/files/ Playing-It-Safe.pdf. Accessed July 1, 2019

21 Liesner RJ, Khair K, Hann IM. The impact of prophylactic treatment on children with severe haemophilia. Br J Haematol 1996;92 (4):973-978

22 Lusher JM, Shapiro SS, Palascak JE, Rao AV, Levine PH, Blatt PM. Efficacy of prothrombin-complex concentrates in hemophiliacs with antibodies to factor VIII: a multicenter therapeutic trial. N Engl J Med 1980;303(8):421-425

23 Ceponis A, Wong-Sefidan I, Glass CS, von Drygalski A. Rapid musculoskeletal ultrasound for painful episodes in adult haemophilia patients. Haemophilia 2013;19(5):790-798

24 Collins PW. Personalized prophylaxis. Haemophilia 2012;18 (Suppl 4):131-135

25 Valentino LA. Considerations in individualizing prophylaxis in patients with haemophilia A. Haemophilia 2014;20(5):607-615

26 Collins PW, Björkman S, Fischer K, et al. Factor VIII requirement to maintain a target plasma level in the prophylactic treatment of severe hemophilia A: influences of variance in pharmacokinetics and treatment regimens. J Thromb Haemost 2010;8(2):269-275

27 Björkman S, Collins P; Project on Factor VIII/Factor IX Pharmacokinetics of the Factor VIII/Factor IX Scientific and Standardization Committee of The ISTH. Measurement of factor VIII pharmacokinetics in routine clinical practice. J Thromb Haemost 2013;11(1): $180-182$

28 Stass H. Determination of minimal sampling time points for reliable pharmacokinetic evaluation of recombinant factor VIII - an exploratory population pharmacokinetic analysis in paediatric patients suffering from severe haemophilia. Haemophilia 2006;12(Suppl 4):50-55

29 Björkman S. Limited blood sampling for pharmacokinetic dose tailoring of FVIII in the prophylactic treatment of haemophilia A. Haemophilia 2010;16(4):597-605

30 Iorio A, Keepanasseril A, Foster G, et al; WAPPS-Hemo co-investigator network. Development of a Web-Accessible Population Pharmacokinetic Service-Hemophilia (WAPPS-Hemo): study protocol. JMIR Res Protoc 2016;5(4):e239

31 Klamroth R, Windyga J, Radulescu V, et al. PK-guided rurioctocog alfa pegol prophylaxis in patients with severe hemophilia $A$ targeting two FVIII trough levels: results from the phase 3 PROPEL study. Res Pract Thromb Haemost 2019;3(Suppl 1):106-107 